\title{
Alternatives for Evaluating the Death Education Student
}

\section{J. Eugene Knott}

The University of Rhode Island

Although grading in postsecondary education, according to Eison and Pollio (1987), dates back about 200 years, the formal pursuit of learning focused on human mortality per se has been a part of higher education for only about thirty years. In that brief period, however, has come a rapidly growing concern with issues of evaluating and grading, paired with concern about motivation for enrollment in such courses in the first place. I've been very interested for some years in self-assessment as it bears on evaluation for grading, especially in courses where the content and approach encourage a great deal of self-disclosure and evaluation is likely to be highly subjective.

The main question which intrigues me centers on whether adult students given the option of choosing weights to be given to the various grading components in a course will use their self-knowledge to optimize their grades. While allowing them to assign those weights may seem like an attempt to dodge responsibility for grading, I think it is responsive to the reality of adult learners, their characteristics, and the body of research which suggests a different, more self-directed approach to much of their formal and informal education. Moreover, I agree with Guskey's assertion that "...procedures for evaluating learning should be congruent with learning objectives" (1988, pp. 62-63).

From To Improve the Academy: Resources for Student, Faculty, and Institutional Development, Vol. 7. Edited by J. Kurfiss, L. Hilsen, S. Kahn, M.D. Sorcinelli, and R. Tiberius. POD/New Forums Press, 1988. 
This paper is a description of one attempt to deal with the grading issue. Specifically, it describes a pilot study in a seminar on "Death, dying, and bereavement" which is offered as an upper division and graduate level three-credit course in alternating semesters. The course is designed to help students: learn the variety of impacts death has on human behavior; see death as a meaningful human experience that can be dealt with; see that death has several significant implications for the living, including determining what choices are valid for oneself and others; be able to apply principles and behaviors of known effectiveness in situations of life and death decision-making and grief for self and others. Students are graded on the basis of their performance on take home quizzes, a written briefing report, and participation in class activities.

The course attracts a fair number of social science and human service students, but, in truth, the major is not a relevant factor in electing this course for most. Many of the students are older than the typical college student and the great majority are women. Most are drawn to the course out of a desire to find a structured way to come to terms with personal issues having to do with loss through death, or to resolve a particular bereavement. They are often candid about those needs, although their notions of the methods by which such resolution might come about are nebulous at best when the course begins. Some openly state that they were drawn to the course by the hope of coming to grips with their own mortality. Others are less candid and claim broader, less personal sounding goals in the first class meetings. Interestingly, each semester, while enrolled in the course, between four and eighteen percent of the students have lost a significant other to death.

\section{Method}

In this modest pilot study I was interested in checking out my guess that students who take this course are more concerned about learning than about grades and, more importantly, I wanted to test a notion about the consequences of allowing students to select their own grade weights. My hypothesis about the latter was that students would get better component and final grades if each decided in advance how much relative weight should be attached to their quizzes, briefing reports, and class activities participation than if I assigned uniform weights to each component for all students.

The LOGO II (Eison, Pollio, and Milton, 1982) was used to examine student orientations toward learning and grading. It was administered during the first class and again at the end of the semester. The test in- 
cludes sixteen items about students' attitudes toward various classroom policies or student learning behaviors. Students respond to them on a strongly agree to strongly disagree scale. Another sixteen items about study attitudes and behaviors call for frequency estimates. The results generate separate learning and grade orientation scores. The primary reason for conducting this study, however, was to find out if students fare better when they can influence the weightings of the elements of the grading system - that is, decide what counts for the most and least number of points in grading. Procedurally, the grade weighting options were described on a "contract" which allowed students to assign percent weights to each of the three graded aspects of the course: three take home quizzes, a briefing report, and class activities participation. The constraints were that the quizzes (collectively) had to count at least $20 \%$, the report at least $25 \%$, and the participation could not count more than $25 \%$. I collected their contracts in the second class and set them aside without looking at them until the end of the semester. I told them about the previous semester's standard weights $(40,35$, and $25 \%)$, which I used for comparison, after they turned in their contracts. I used a MacIntosh computer and an Excel spreadsheet to keep track of the data and compare the weighted grades.

\section{Results and Discussion}

The LOGO II results were about as expected: the mean Learning Orientation Total score at the beginning of the semester was 54.91 for the 11 students in the course. Their average Grade Orientation score was 35.82. That would put them above the 80th percentile on Learning Orientation, and below the 20 th on Grade Orientation, on a set of norms based on a sample of 812 students at the University of Tennessee, Knoxville (Eison, undated). Their mean scores were essentially the same at the end of the semester. There was a tendency, albeit statistically insignificant, toward learning orientation being highest in the oldest students and grade orientation highest in the youngest.

The weights assigned to each grading component by students, and the component and total scores each received, are reported in Table 1, along with comparison weights and scores based on the previous semester's grading system. No student assigned weights which matched my comparison system. One result was that the component scores of individuals varied quite dramatically from what they would have been if I had applied a standard weighting system. Even so, no total score was more than six tenths of a point different than it would have been, and the mean total 


\section{TABLE 1}

\section{Grading Component Weights and Scores}

Raw scores (r-score) and student (S) and instructor (I) weights and weighted scores (w-score)

\begin{tabular}{|c|c|c|c|c|c|c|c|c|}
\hline \multirow[b]{2}{*}{ Student } & \multicolumn{2}{|c|}{ Quizzes } & \multicolumn{2}{|c|}{ Participation } & \multicolumn{2}{|c|}{ Report } & \multicolumn{2}{|c|}{ Final Score } \\
\hline & $S$ & I & $\mathbf{S}$ & I & $\mathbf{S}$ & I & $\mathbf{S}$ & I \\
\hline r-score & 90.0 & & 87.0 & & 90.0 & & & \\
\hline 01 weights & $40 \%$ & $40 \%$ & $25 \%$ & $35 \%$ & $35 \%$ & $25 \%$ & & \\
\hline w-score & 36.0 & 36.0 & 21.8 & 30.5 & 31.5 & 22.5 & 89.3 & 89.0 \\
\hline r-score & 92.0 & & 87.0 & & 93.0 & & & \\
\hline 02 weights & $30 \%$ & $40 \%$ & $45 \%$ & $35 \%$ & $25 \%$ & $25 \%$ & & \\
\hline w-score & 27.6 & 36.8 & 39.2 & 30.5 & 23.3 & 23.3 & 90.0 & 90.5 \\
\hline r-score & 92.0 & & 87.0 & & 93.0 & & & \\
\hline 03 weights & $45 \%$ & $40 \%$ & $40 \%$ & $35 \%$ & $15 \%$ & $25 \%$ & & \\
\hline w-score & 41.4 & 36.8 & 34.8 & 30.5 & 14.0 & 23.3 & 90.2 & 90.5 \\
\hline r-score & 88.0 & & 90.0 & & 90.0 & & & \\
\hline 04 weights & $50 \%$ & $40 \%$ & $25 \%$ & $35 \%$ & $25 \%$ & $25 \%$ & & \\
\hline w-score & 44.0 & 35.2 & 22.5 & 31.5 & 22.5 & 22.5 & 89.0 & 89.2 \\
\hline r-score & 91.0 & & 90.0 & & 90.0 & & & \\
\hline 05 weights & $30 \%$ & $40 \%$ & $45 \%$ & $35 \%$ & $25 \%$ & $25 \%$ & & \\
\hline w-score & 27.3 & 36.4 & 40.5 & 31.5 & 22.5 & 22.5 & 90.3 & 90.4 \\
\hline r-score & 87.0 & & 84.0 & & 87.0 & & & \\
\hline 06 weights & $20 \%$ & $40 \%$ & $55 \%$ & $35 \%$ & $25 \%$ & $25 \%$ & & \\
\hline w-score & 17.4 & 34.8 & 46.2 & 29.4 & 21.8 & 21.8 & 85.4 & 86.0 \\
\hline r-score & 88.7 & & 90.0 & & 93.0 & & & \\
\hline 07 weights & $45 \%$ & $40 \%$ & $30 \%$ & $35 \%$ & $25 \%$ & $25 \%$ & & \\
\hline w-score & 39.9 & 35.5 & 27.0 & 31.5 & 23.3 & 23.3 & 90.2 & 90.2 \\
\hline r-score & 83.7 & & 84.0 & & 90.0 & & & \\
\hline 08 weights & $50 \%$ & $40 \%$ & $25 \%$ & $35 \%$ & $25 \%$ & $25 \%$ & & \\
\hline w-score & 41.8 & 33.5 & 21.0 & 29.4 & 22.5 & 22.5 & 85.3 & 85.4 \\
\hline r-score & 91.0 & & 87.0 & & 90.0 & & & \\
\hline 09 weights & $45 \%$ & $40 \%$ & $30 \%$ & $35 \%$ & $25 \%$ & $25 \%$ & & \\
\hline w-score & 41.0 & 36.4 & 26.1 & 30.5 & 22.5 & 22.5 & 89.6 & 89.4 \\
\hline
\end{tabular}

(Continued on next page.) 
TABLE 1-Continued.

\begin{tabular}{cccccccccc}
\hline & \multicolumn{2}{c}{ Quizzes } & \multicolumn{2}{c}{ Participation } & \multicolumn{2}{c}{ Report } & \multicolumn{2}{c}{ Final Score } \\
Student & S & I & S & I & S & I & S & I \\
\hline r-score & 88.0 & \multicolumn{9}{c}{90.0} & \multicolumn{3}{c}{90.0} & & & \\
10 weights & $35 \%$ & $40 \%$ & $40 \%$ & $35 \%$ & $25 \%$ & $25 \%$ & & \\
w-score & 30.8 & 35.2 & 36.0 & 31.5 & 22.5 & 22.5 & 89.3 & 89.2 \\
& & & & & & & & & \\
r-score & 87.0 & & 84.0 & & 90.0 & & & \\
11 weights & $40 \%$ & $40 \%$ & $40 \%$ & $35 \%$ & $20 \%$ & $25 \%$ & & \\
w-score & 34.8 & 34.8 & 33.6 & 29.4 & 18.0 & 22.5 & 86.4 & 86.7
\end{tabular}

Note. All raw scores have a maximum value of 100 ; weighted scores are weights $\mathrm{x}$ raw scores. The quiz raw score is a mean of the three take home quiz scores.

scores were virtually identical under the two systems (88.6 and 88.7). In effect, having the option of deciding for themselves how to weight the graded components of the course had no discernable impact on any student's grade.

In summary, this research in a seminar on death and dying found that these eleven students were indeed much more learning than grade oriented but, counter to my expectations, electing their own grading weights did not result in higher (or lower) grades for any of them. I am not surprised by the high learning orientation of these students and expect that that finding could be replicated repeatedly in this course. But I am puzzled by the lack of more pronounced effects from the self-determined grading weights option. I expected to find their ability to take rightful advantage of self-knowledge to optimize grades borne out in the final scores.

I suspect that a grading format which included in-class exams in the mix might turn up more support for my original hypothesis. As is evident from Table 1, there was substantial variability within and across students in the weights chosen for each component. There was not, however, much variability in raw scores for individual students or the class as a whole. Adding in-class exams would almost certainly increase that variability dramatically and make possible a more conclusive test of my basic hypothesis.

Given that the grading elements which I have been using seem more appropriate to my course goals, however, I'm not likely to add in regular examinations. But, because the feedback from students about the selfdetermination option was so enthusiastically and uniformly positive, I will 
keep it for this course in the future. Perhaps the element of perceived influence and control of outcomes (and reduced grade anxiety?), albeit in students with more concern about learning than grading, is sufficient justification for its retention in the course. And, as mentioned earlier, this particular subject matter and students' reasons for taking the course seem to call for special considerations.

\section{References}

Eison, J. (undated). Recognizing and responding to learning style differences. Unpublished manuscript, Southeast Missouri State University, Center for Teaching and Learning, Cape Girardeau.

Eison, J., \& Pollio, H. (1987). A multidimensional approach to the definition of college students' learning. Joumal of College Student Personnel. 27, 434-443.

Eison, J., Pollio, H., and Milton, O. (1982). Manual for use with LOGO II. Knoxville, TN: Learning Research Center, The University of Tennessee.

Guskey, T. R. (1988). Improving student learning in college classrooms. Springfield, IL: C. C. Thomas. 